\title{
Production-associated risk factors of seismicity in the Kiirunavaara mine
}

\author{
J Vatcher Itasca Consultants $A B$, Sweden \\ M Bošković Luossavaara-Kiirunavaara Aktiebolag (LKAB), Sweden \\ J Sjöberg Itasca Consultants $A B$, Sweden
}

\begin{abstract}
When it comes to deep mining, the geomechanical risks of production planning decisions are amplified due to the high-loading environment and typical deep rock mass behaviour such as seismic activity, ground falls, spalling, strainbursting, and rockbursting. Assessing how production decisions influence hazards is an important aspect of risk assessment. A preliminary analysis of the historic production at the Luossavaara-Kiirunavaara Aktiebolag (LKAB) Kiirunavaara mine indicated a significant likelihood of ore/host rock remnants after production blasting in some volumes of the mine. These remnants are caused by a combination of drill fan geometry, orebody geometry, safety regulations minimising the likelihood for drill breakthrough, and typical limitations of blasting practices. Numerical stress analysis modelling was used for a selected volume of the mine critical to production to evaluate the effect of possible geometric realisations of the production remnants. A qualitative risk assessment of the production remnants was completed, with focus on results that indicated seismically active volumes. The understanding gained from this work is important to the mine's future production planning, as it gives insight into factors that increase the risk of seismicity.
\end{abstract}

Keywords: risk factors, production planning, numerical modelling, uncertainty

\section{Introduction}

Long- and short-term production decisions influence rock mass behaviour and the consequences of these decisions can be amplified in deep mines that are seismically active. It is widely accepted that the production schedule can be used to manage the risks of deep rock mass behaviour, with techniques such as stressshedding and just-in-time development, for example, the chevron production sequence adopted by Laronde Mine, as described by Potvin and Wesseloo (2013). It is equally important to plan not only the order of what is excavated, but to also understand what rock is left behind, as remnants can also influence the stress distribution and therefore rock mass behaviour. Unplanned remnants are a function of many design decisions, such as mining method, blasting practices, and layout in the given geomechanical environment. In some cases, it may be important to understand if remnants, both planned and unplanned, may add additional risk to deep rock mass behaviour. A greater understanding of how design decisions influence rock mass behaviour will lead to proactive, risk mitigating design.

This paper explores the potential influence of production decisions on rock mass behaviour at the Luossavaara-Kiirunavaara Aktiebolag (LKAB) Kiirunavaara mine, focused on mining-induced seismicity. The mine consists of a large, approximately $4.5 \mathrm{~km}$ long orebody in which the iron ore is extracted by sublevel caving. Preliminary analysis of historic production in a specific $900 \mathrm{~m}$ long volume in the mine showed that it is possible that both:

1. Remnants exist in the tops of blasted sublevel caving rings, forming pillars of unknown thicknesses due to the production layout.

2. Remnants exist where production has been planned to avoid waste rock, such as a stiffer dyke unit. 
The effect of different possible geometric realisations of the production remnants on rock mass behaviour was evaluated using numerical modelling as a laboratory to test different scenarios. A qualitative risk assessment of these possible realisations was completed, with a focus on mining-induced seismicity.

This analysis is limited to a specific volume in the mine, called Block 19/22. Currently, data exists that suggests the presence of these potential remnants. This is the first stage in work to identify if such remnants pose significant risk to evaluate if further investigation is required. This paper provides a background to the Kiirunavaara mine and previous related works, followed by a description of the models, results and discussion, and concluding remarks.

\section{Kiirunavaara mine and production}

The Kiirunavaara mine is located approximately $200 \mathrm{~km}$ north of the Arctic Circle in Sweden. The orebody has a northerly strike, aligned with the mine's $y$-axis. The orebody dips approximately east, aligned with the mine's $x$-axis, typically between $50^{\circ}$ and $70^{\circ}$. The orebody ranges in thickness from a few meters to over a hundred meters. Sublevel caving is used to extract the ore, where angled production fans are drilled (upwards) in the orebody, and production progresses downwards as well as from the hanging wall towards the footwall. Ore is loaded at the faces and then sent through ore passes to the main haulage level where a rail system takes the ore to a skip leading to surface. A sketch of this process is shown in Figure 1.

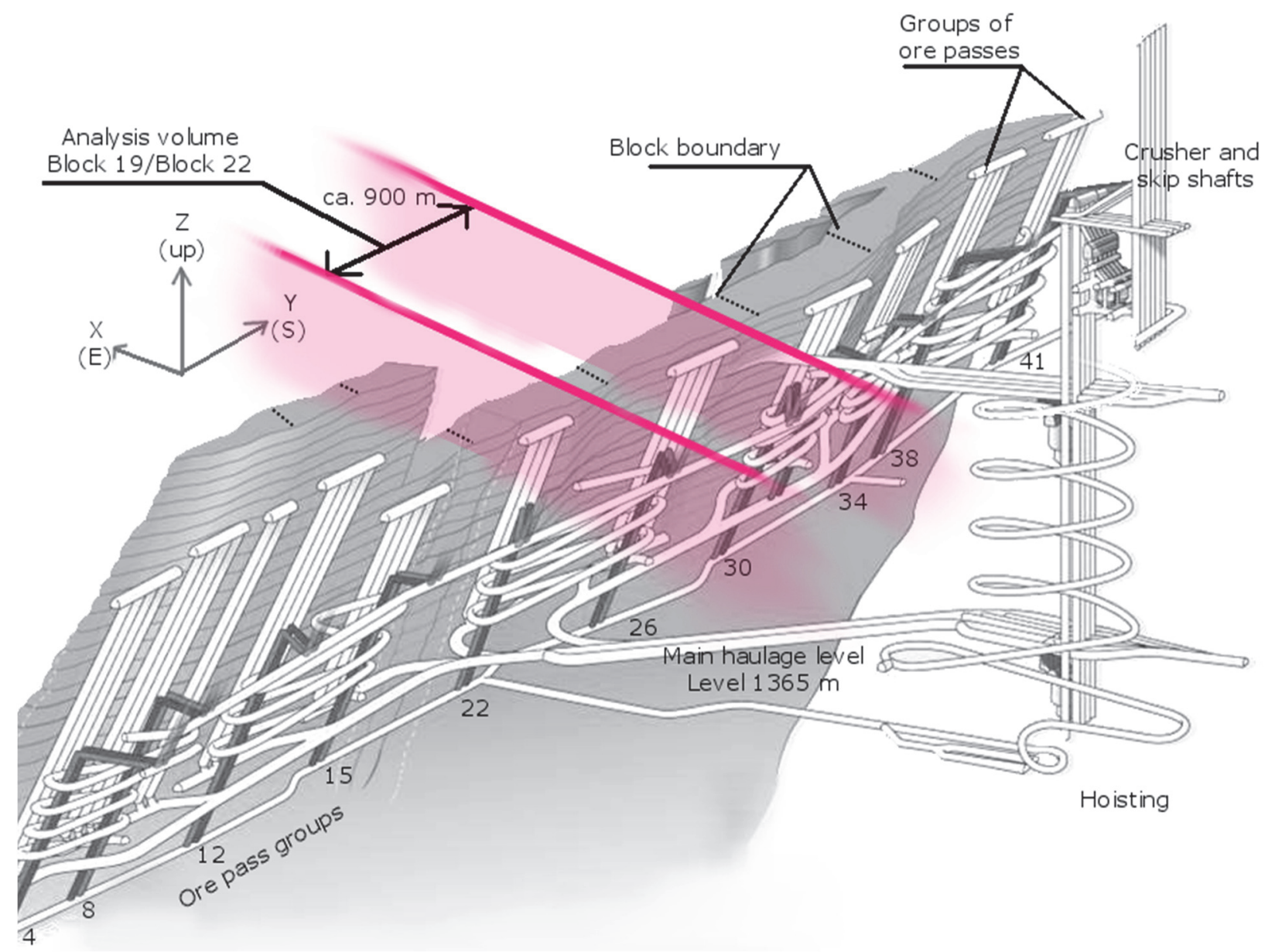

Figure 1 Sketch of mining activities in the Kiirunavaara mine (modified from LKAB)

The mine is divided into production blocks, typically a few hundred meters in length along the $y$-axis, according to their $y$-coordinate. With the change in the main haulage level at Level $993 \mathrm{~m}$ to a deeper main haulage level, the block names change (for example above Level $993 \mathrm{~m}$ it is called Block 19, whereas below that level it is referred to as Block 22). In the central portion of Block 19/22, the orebody thins significantly. At some places in this volume, the footwall contacts the hanging wall (no ore). 
Typical production at the Kiirunavaara mine has crosscuts and production fans transversely across the orebody. However, where the ore is thin in Block 19/22, production has been planned longitudinally, where production drifts and fans follow the strike of the orebody (Figure 2).

\section{Orebody strike}

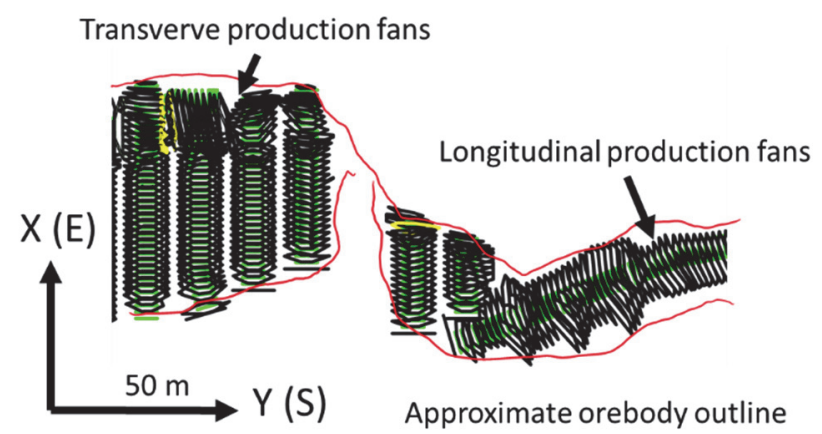

(a)

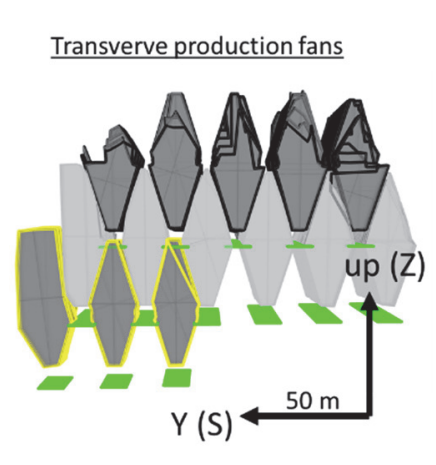

(b)
Longitudinal production fans
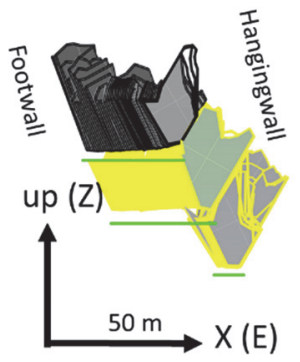

Figure 2 Sketches of transverse versus longitudinal sublevel caving production at the Kiirunavaara mine. (a) Plan view; (b) Views perpendicular to the production fans

Remnants after blasting are a relatively common occurrence in mining. In a cave mine, one relies on these remnants caving for the mining method to function correctly. Remnants in the Kiirunavaara mine can be caused by a combination of drill fan geometry, orebody geometry, safety regulations minimising the likelihood for drill breakthrough, ground conditions, and typical limitations of blasting practices.

There are indications that unplanned remnants exist and are potentially problematic. For example, seismic events have been located inside of the volume that should be caved. It is also known that blasting in some volumes in the mine, particularly where longitudinal fans are employed, has encountered some difficulties. Since the mine drills and loads upwards, it is believed that the majority of unplanned remnants would be in the uppermost portion of the fans.

Previous models of the Kiirunavaara mine have, for the most part, significantly simplified extraction. For example, Vatcher (2017) represented production at the mine-scale as the removal of ore in one level and production block in its entirety when production commenced in each volume. The exception to this is the work of Sjöberg et al. (2011), where the authors used numerical modelling to complete a forensic analysis of a rockburst event in Block 19. This model included drifts and simplified fans. The potential issues created by specific fan geometry, production sequencing, and blasting efficiency have not previously been evaluated in $3 \mathrm{D}$ at the Kiirunavaara mine.

\section{$3 \quad$ Numerical models and procedure}

Itasca's 3D finite difference continuum numerical modelling software FLAC3D (Itasca Consulting Group, Inc. 2018) was selected for this analysis. When considering the issue of planned and unplanned remnants in 3D space and their effect upon mining-induced stresses in the Kiirunavaara mine, plane-strain conditions do not exist. The 3D geometry of the orebody combined with the mining layout requires a 3D numerical model. It is not expected that structures contribute significantly to the problem at hand (e.g. Vatcher 2017), so for this level of analysis continuum models were deemed appropriate.

One model geometry was used to evaluate different cases. This project includes four cases, and results from the first two are presented in this paper. The four cases include:

1. Base case: planned remnants represented, no unplanned remnants were represented.

2. $10 \mathrm{~m}$ horizontal sill pillar case: planned remnants represented, approximately $10 \mathrm{~m}$ thick pillar left directly under each level, stretching the length of the model (theoretical case). 
3. Pillars: approximately $5 \mathrm{~m}$ thick pillars left in the top of each fan (theoretical case).

4. Loading grade pillars: where the percent loading grade for each fan is used to estimate the percent material remaining in each fan as a remnant pillar.

Comparison of model results to specific seismic events and seismically active areas is planned to be evaluated in the future. Figure 3 shows the extents of the numerical model using mine coordinates. The model is $1,600(\mathrm{w}) \times 900(\mathrm{l}) \times 1,300 \mathrm{~m}(\mathrm{~h})$. Definition exists between the footwall, ore, and hanging wall material. The geometry of the ore in the model is based closely on information provided by LKAB.

Drifts and production fans are included in the model (Figure 4).

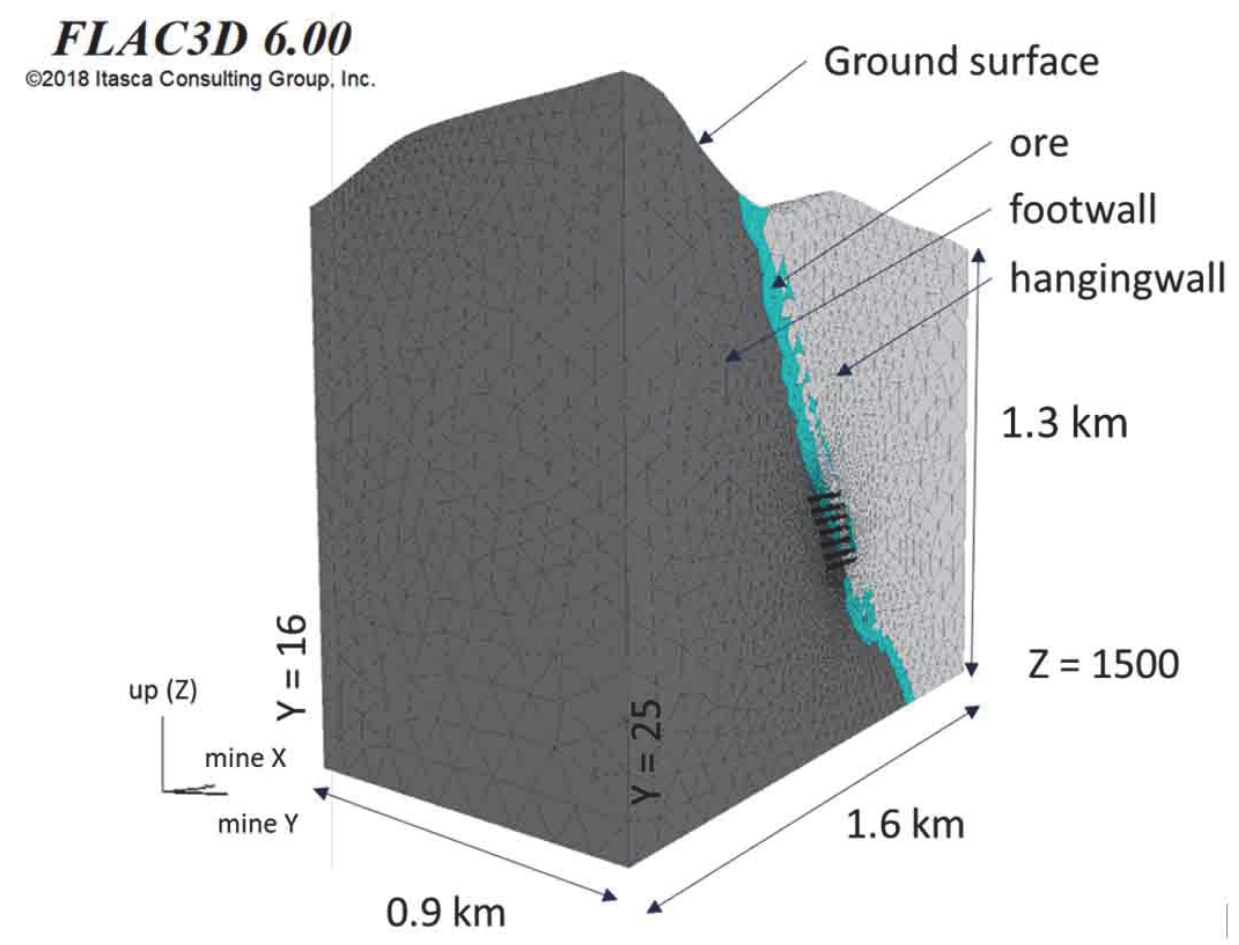

Figure 3 Isometric view of numerical model showing the footwall, hanging wall and orebody. Coordinates are in mine coordinates

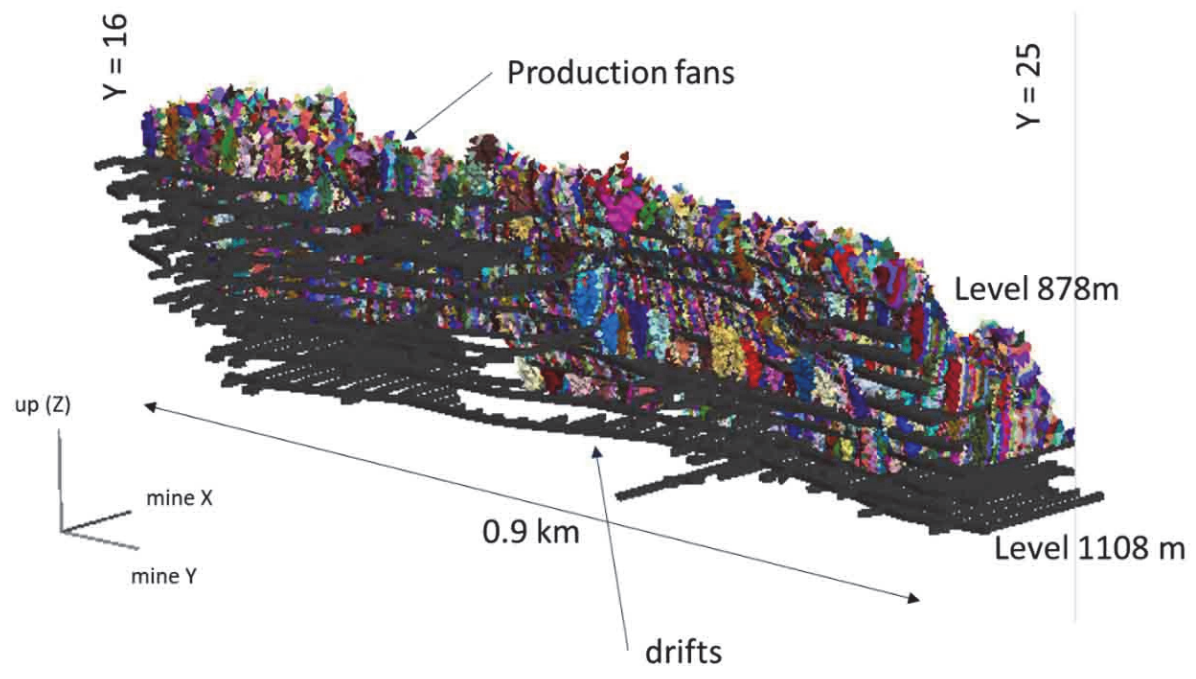

Figure 4 Isometric view of the drifts and production fans from 2005 to 2018 in the numerical model, from footwall towards hanging wall 
Detailed production information by fan was available for nine levels in the mine in Block 19/22 (from Level $878 \mathrm{~m}$ to Level $1108 \mathrm{~m}$ ). All fans on each of the nine levels in the analysis volume were included in the model. Production on Level $878 \mathrm{~m}$ in Block 19/22 began in 2005. Production prior to this (above Level $878 \mathrm{~m}$ ) was extracted simultaneously in the model with all drifts before detailed, fan-based production was represented. Production is represented by the removal of the material inside of individual fans, with no adjustment to the caved material in the hanging wall. With consideration to analysis and computation time, the models were run to equilibrium annually, providing a snapshot of the exact production configuration at the beginning of each year from 2005 and forward.

A Mohr-Coulomb perfectly plastic constitutive model was used. This was deemed the most appropriate model considering the circumstances as shear failure is expected due to high stresses at depth and based on available input data. Input data for the three geomechanical units (footwall, ore, and hanging wall) was taken from the often used values of Sjöberg et al. $(2003,2012)$ and is presented in Table 1. Like previous models of the Kiirunavaara mine, no changes were made to the properties of the material expected to cave.

Table 1 Material properties used in the models (Sjöberg et al. 2003, 2012)

\begin{tabular}{llll}
\hline Property & Footwall & Ore & Hanging wall \\
\hline Young's modulus, E & $70 \mathrm{GPa}$ & $65 \mathrm{GPa}$ & $70 \mathrm{GPa}$ \\
Poisson's ratio, $v$ & 0.27 & 0.25 & 0.22 \\
Density, $\rho$ & $2,800 \mathrm{~kg} / \mathrm{m}^{3}$ & $4,700 \mathrm{~kg} / \mathrm{m}^{3}$ & $2,700 \mathrm{~kg} / \mathrm{m}^{3}$ \\
Cohesive strength, $\mathrm{C}$ & $10.2 \mathrm{MPa}$ & $6.88 \mathrm{MPa}$ & $6.68 \mathrm{MPa}$ \\
Tensile strength, $\mathrm{T}$ & $2.23 \mathrm{MPa}$ & $1.21 \mathrm{MPa}$ & $1.00 \mathrm{MPa}$ \\
Friction angle, $\phi$ & $58.2^{\circ}$ & $54.3^{\circ}$ & $55.1^{\circ}$ \\
\hline
\end{tabular}

Initial stresses applied in the model were based on the relationships developed by Sandström (2003) for the Kiirunavaara mine. This initial stress state resulted in an induced stress field at depth in numerical models that closely matched independent stress measurements (Vatcher et al. 2014).

$$
\begin{gathered}
\sigma_{e w}=\sigma_{x(\text { mine })}=0.037 \mathrm{z} \\
\sigma_{n s}=\sigma_{y(\text { mine })}=0.028 \mathrm{z} \\
\sigma_{\text {vertical }}=\sigma_{z \text { (mine })}=0.029 \mathrm{z}
\end{gathered}
$$

where:

$$
\begin{aligned}
& z \quad=\text { depth below surface }(\mathrm{m}) . \\
& \sigma \quad=\text { stress (MPa), provided in Cartesian directions in mine coordinates. }
\end{aligned}
$$

\section{$4 \quad$ Results}

Results on multiple evaluation planes at different points in time were analysed. A summary of the more notable results is presented here. In general, the presence of horizontal remnants at the top of the fans has the potential to influence rock mass behaviour. Stresses concentrate in the $10 \mathrm{~m}$ thick remnants, as shown in an example of production at the beginning of 2018 on a vertical slice through $Y=19$ in Figure 5. The major principal stresses concentrate in the form of a band through the remnant pillar, between the open stope volumes above and below the remnant pillar. It is also evident that pillars result in a more compressive environment for the host rock, extending long into the footwall and hanging wall.

This banding effect of major principal stress appears to have the strongest magnitude when the ore and production volume is thin, like shown for $Y=19$ (Figure $6(b)$ ). When the ore and production volume is thicker, however, the banding is less distinct, and the concentration of major principal stress has a lower magnitude 
(Figure5(c)). This phenomenon is also present in other areas of the model where the ore and therefore production volume is thicker.

These remnant pillars also exhibit low minimum principal stresses (Figure 6). However, of particular interest is the effect of remnant pillars on the minimum principal stresses in the surrounding host rock. As evident in Figure 6, pillars result in an environment with higher minimum principal stresses in the host material.

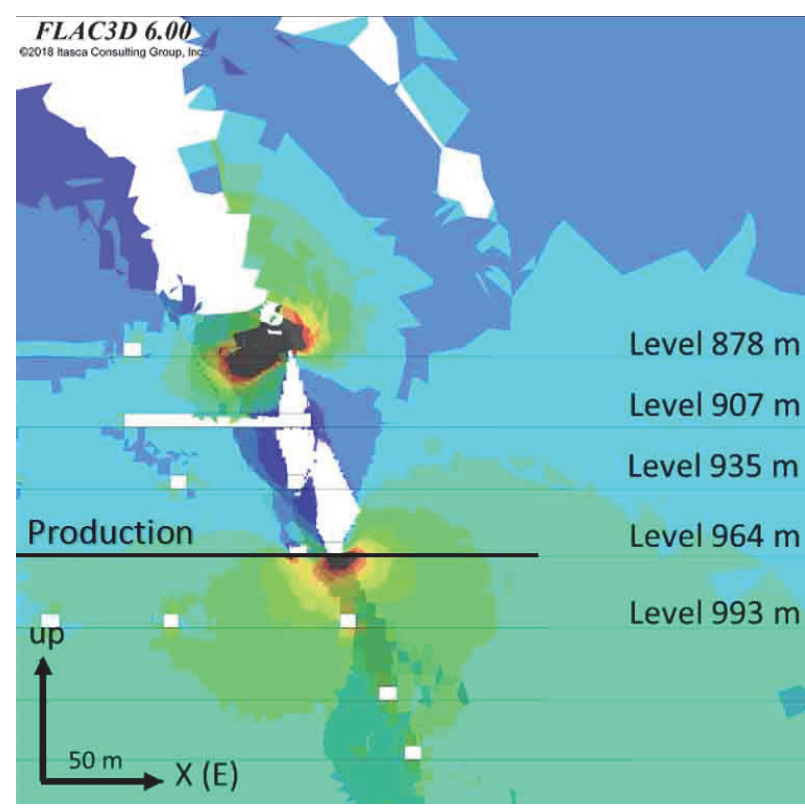

(a)

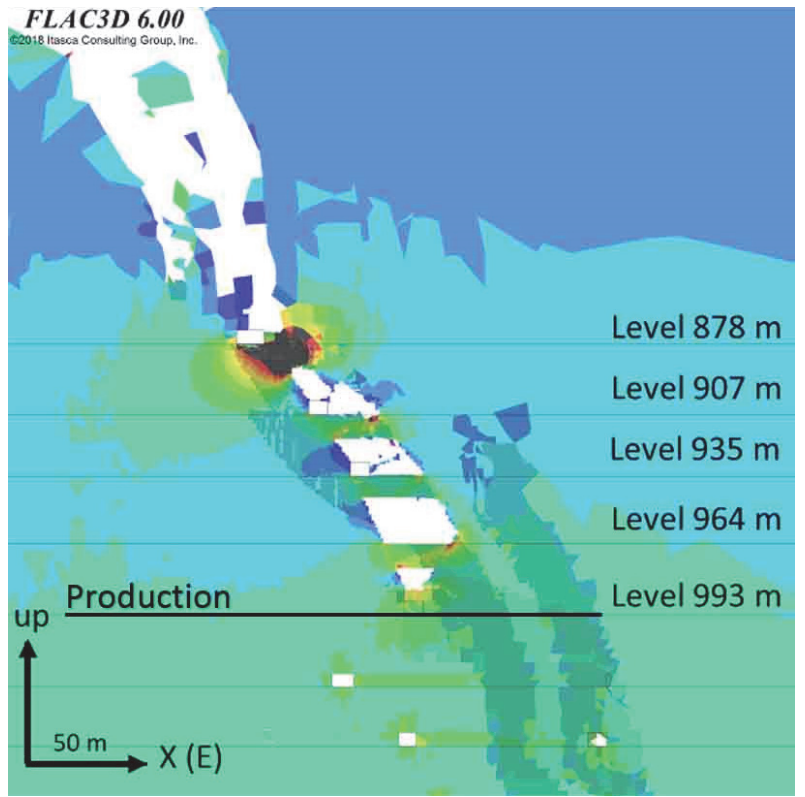

(c)

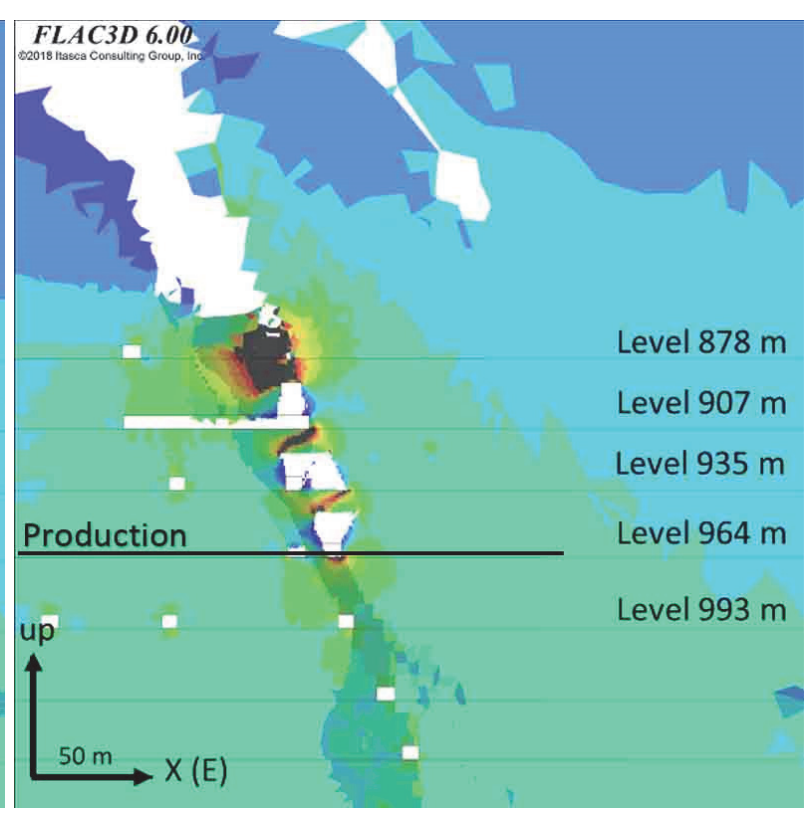

(b)

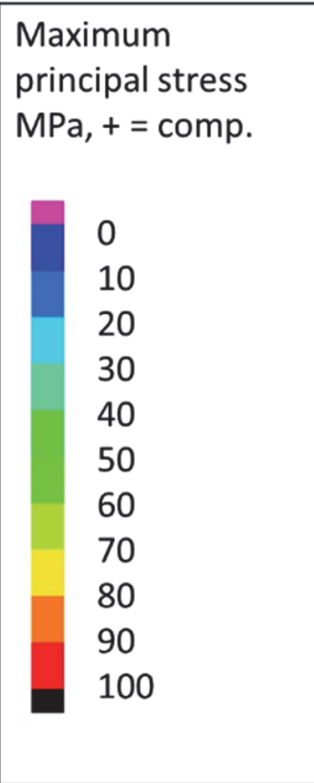

Figure 5 Major principal stress induced by mining at the beginning of 2018. (a) Base case (no remnants), $Y=19$; (b) $10 \mathrm{~m}$ thick remnants, $Y=19$; (c) $10 \mathrm{~m}$ thick remnants, $Y=22$ at the top of the production fans. Viewed from south (positive $Y$ ) to north on vertical planes 


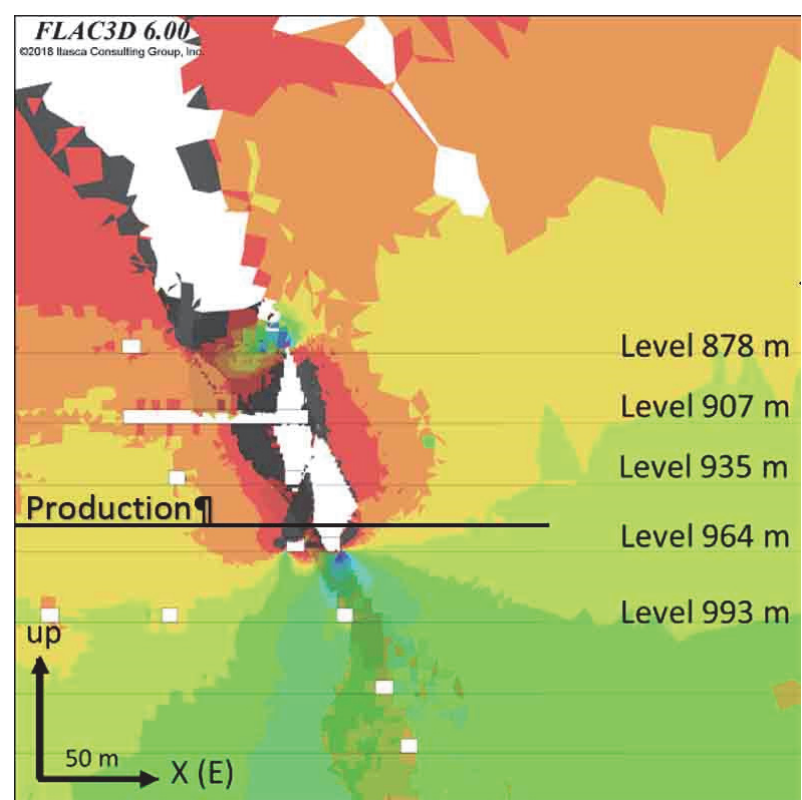

(a)

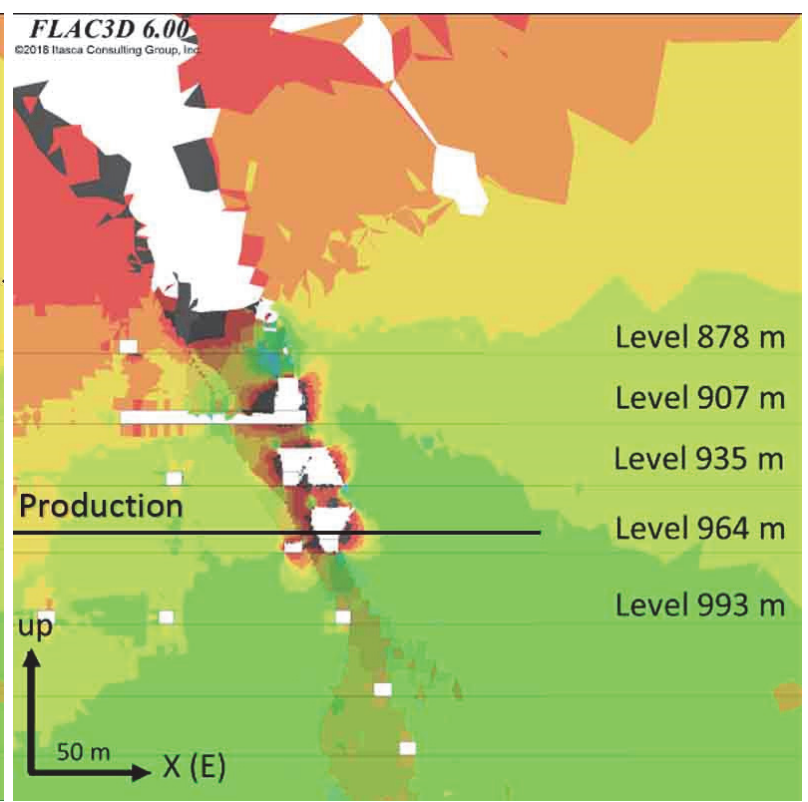

(b)

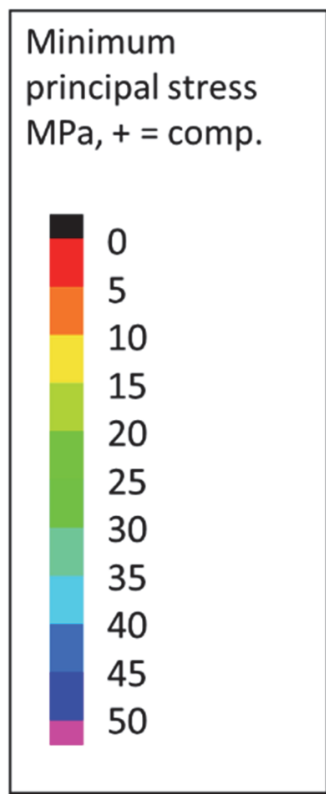

Figure 6 Minor principal stress induced by mining at the beginning of 2018. (a) Base case (no remnants); (b) $10 \mathrm{~m}$ thick remnants at the top of the production fans. Viewed from south (positive $Y$ ) to north on a vertical plane at $Y=19$

These stress changes induced by the remnant pillars can be important to rock mass behaviour, in particular seismicity. Known proxies for seismicity caused by crack initiation (not fault slip) are differential stress and plastic yield. Diederichs (2000) showed that crack initiation occurs when differential stress is a fraction of unconfined compressive strength of the rock, and Pierce at al. (2006) found that coefficient to be 0.35 for the Kiirunavaara mine. According to data analysis completed by Vatcher et al. (2016), the footwall strength is approximately $200 \mathrm{MPa}$, thereby the threshold of differential stress for crack initiation is $70 \mathrm{MPa}$. Values greater than this threshold of $70 \mathrm{MPa}$ are shown in black in all differential stress plots.

Figure 7 illustrates the differential stress at the beginning of 2018 for both cases. The case without remnants has a larger concentration of high differential stresses under the active production level (Figure 8(a)) that even involves the footwall drift. However, for the case with the remnants, the differential stresses concentrated in the remnant pillars, and the extent of high differential stress was reduced under the active production level. 
These are relatively large volumes of rock that are likely undergoing crack initiation. The presence of horizontal remnant pillars has the potential to affect the location and extent of volumes that are seismically active.

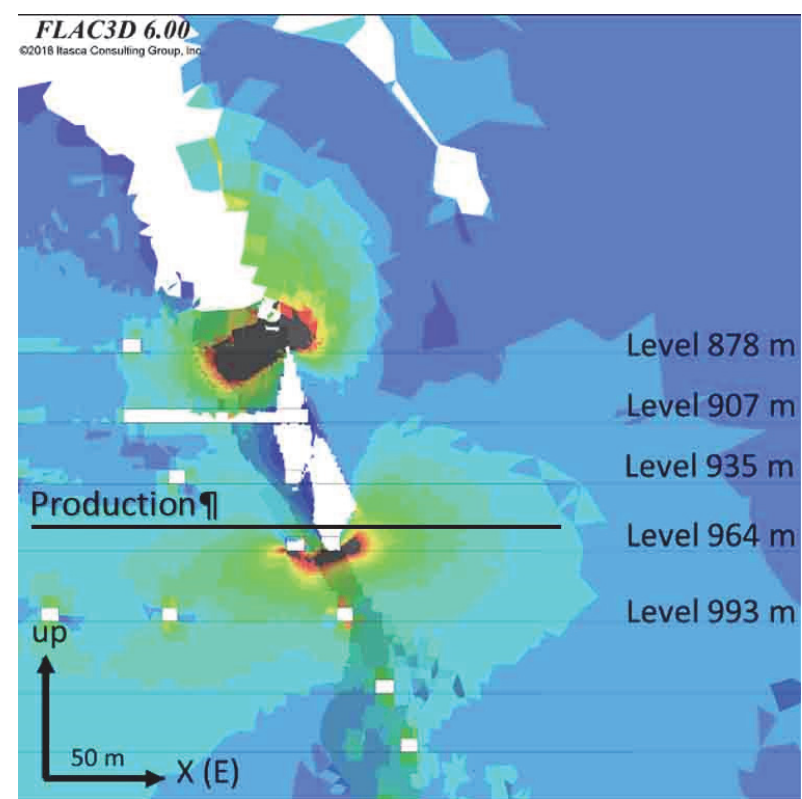

(a)

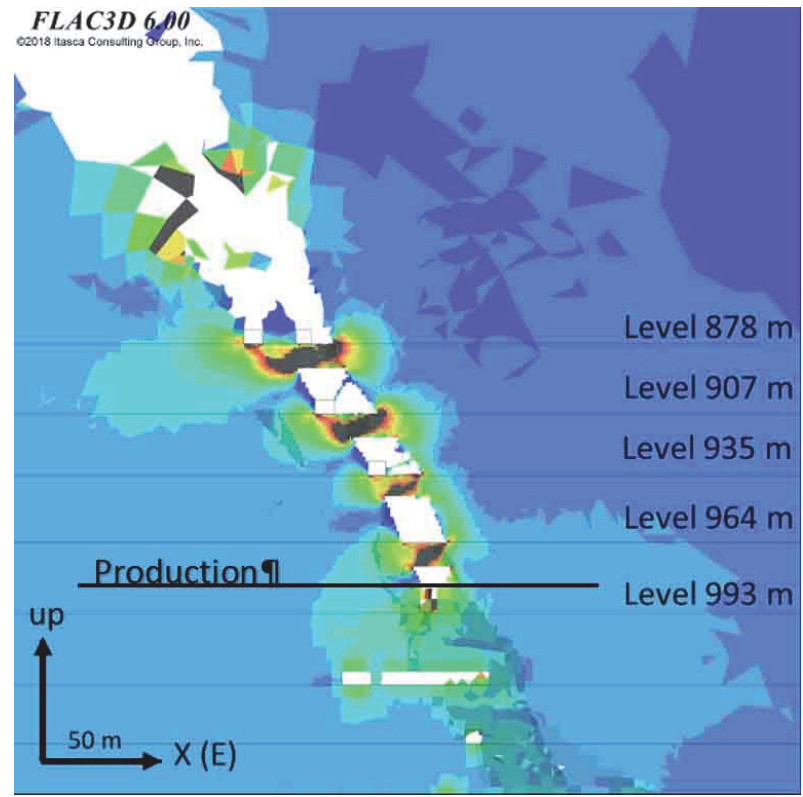

(c)

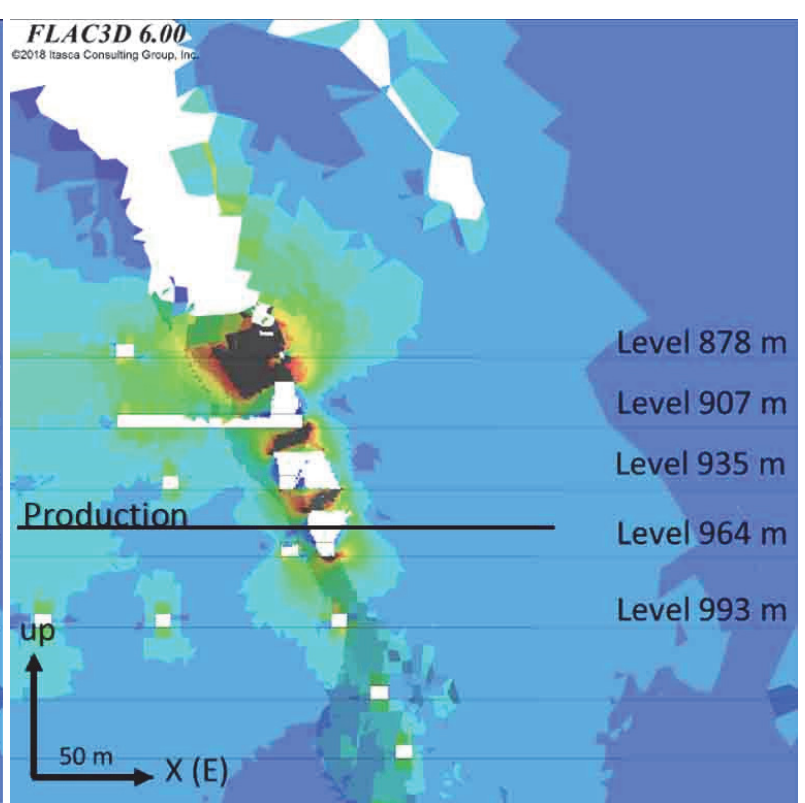

(b)

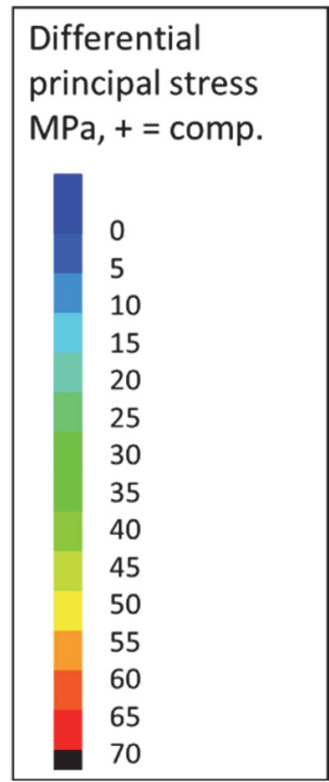

Figure 7 Differential stress induced by mining at the beginning of 2018. (a) Base case (no remnants), $Y=19$; (b) $10 \mathrm{~m}$ thick remnants, $\mathrm{Y}=19$; (c) $10 \mathrm{~m}$ thick remnants, $\mathrm{Y}=22$ at the top of the production fans. Viewed from south (positive $Y$ ) to north on vertical planes

Plastic yield is another way in numerical modelling to partially evaluate seismic behaviour. Seismicity concentrates outside of the plastically yielded volumes, for example Andrieux et al. (2008). Figure 8 illustrates the plastic yield for the two cases evaluated. While there is limited extent of plastic yield at the mine-scale, the remnant pillars have significant volumes of plastic yield. It is interesting to consider that although there is a large amount of plastic yield in these remnant pillars, they still have a high concentration of stress. 


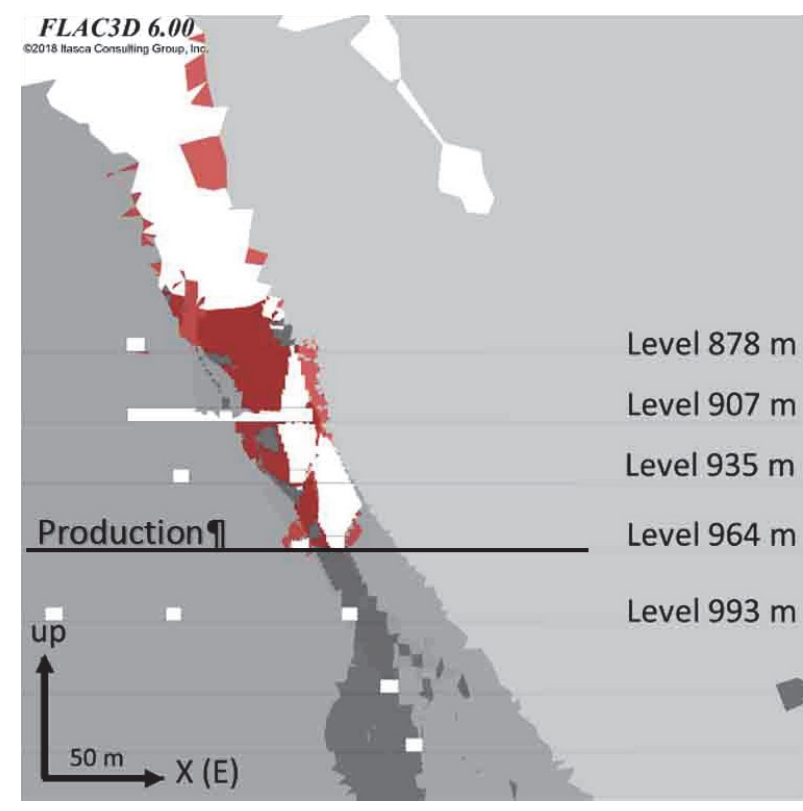

(a)

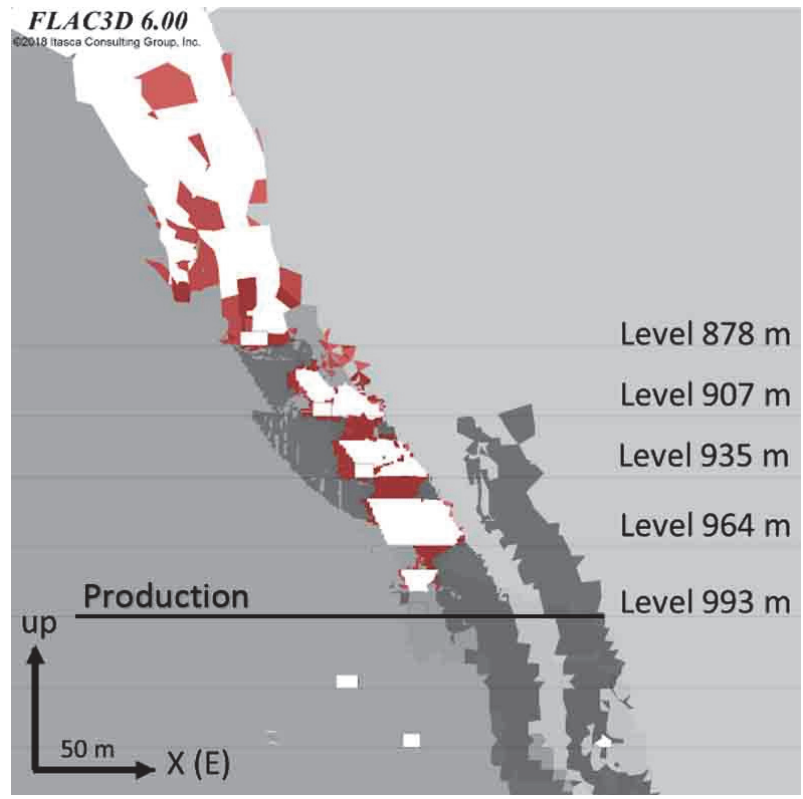

(c)

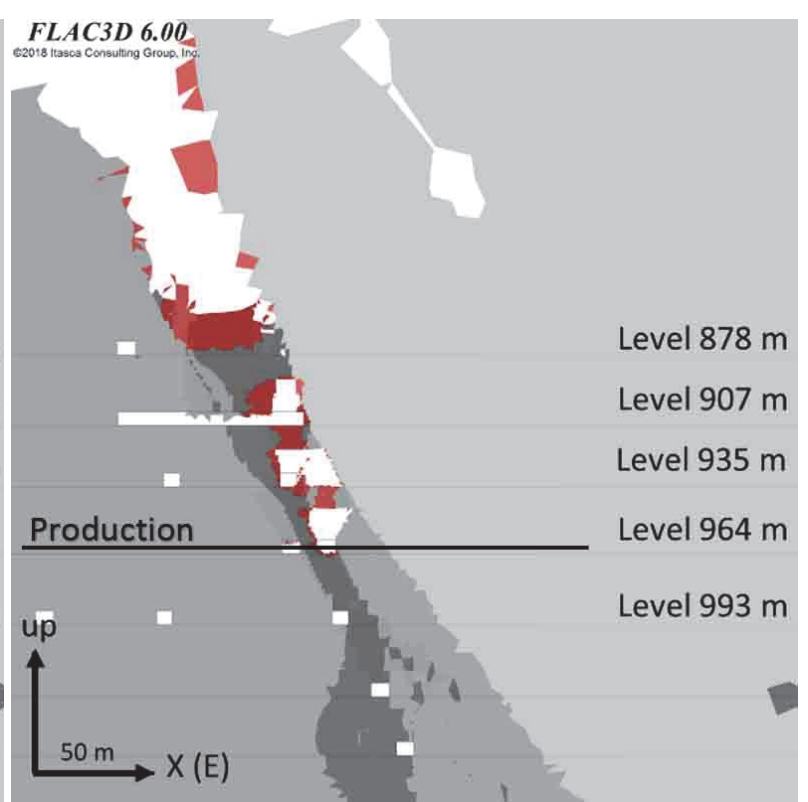

(b)

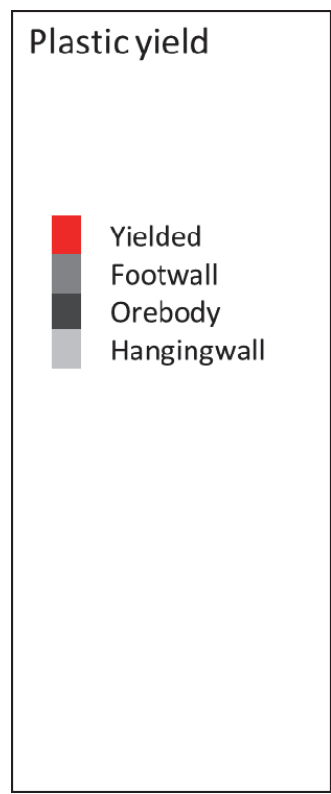

Figure 8 Plastic yield at the beginning of 2018. (a) Base case (no remnants), $Y=19$; (b) $10 \mathrm{~m}$ thick remnants, $Y=19$; (c) $10 \mathrm{~m}$ thick remnants, $Y=22$ at the top of the production fans. Viewed from south (positive $Y$ ) to north on vertical planes

These results show that if production remnants exist at the Kiirunavaara mine, they can influence seismic rock mass behaviour through inducing stress field changes. Table 2 provides the qualitative risk assessment for the two cases evaluated, without remnant pillars and with $10 \mathrm{~m}$ thick remnant sill pillars, with a focus on risk to personnel. While we currently do not have a situation where sill pillars exist (since the mine is successfully caving), this shows an extreme example and provides some insight into how changing the mining method with depth may influence risk. Risk is evaluated for each case near production and near the remnant pillars, as the exposure and results are distinct for these two locations.

The 'Exposure' column in Table 2 refers to the likelihood of workers being present in each location. Currently, there are many workers near production, and fewer workers in the completed levels where the pillars would be left. Hazard refers to the model results, where differential stress and seismicity indicated potential seismic 
activity. In the model without remnant pillars, there is a very large volume near production that experiences high differential stress, which can be indicative of seismicity caused by crack initiation. However, when remnant sill pillars were present, the volume indicative of seismicity near production reduced, leaving a concentration of high differential stresses in the sill pillars themselves. Therefore, it is deemed that the presence of such long sill pillars reduces the risk associated with seismic activity near production. This information can be useful if the mine is to change mining method with increasing depth.

Table 2 Qualitative risk assessment

\begin{tabular}{|c|c|c|c|c|}
\hline Case & Location & $\begin{array}{l}\text { Exposure } \\
\text { Likelihood of workers } \\
\text { present in the location }\end{array}$ & $\begin{array}{l}\text { Hazard } \\
\text { Based on model results } \\
\text { of seismically active } \\
\text { volumes }\end{array}$ & $\begin{array}{l}\text { Risk assessment } \\
\text { Considering exposure } \\
\text { and hazard }\end{array}$ \\
\hline \multirow{2}{*}{$\begin{array}{l}\text { No } \\
\text { remnant } \\
\text { pillars }\end{array}$} & $\begin{array}{l}\text { Near } \\
\text { production }\end{array}$ & Currently many workers & Moderate & Moderate \\
\hline & $\begin{array}{l}\text { Near } \\
\text { remnant } \\
\text { pillars }\end{array}$ & $\begin{array}{l}\text { Currently no pillars (few } \\
\text { workers where they } \\
\text { would be) }\end{array}$ & N/A & N/A \\
\hline \multirow{2}{*}{$\begin{array}{l}\text { Remnant } \\
\text { sill pillar } \\
10 \mathrm{~m}\end{array}$} & $\begin{array}{l}\text { Near } \\
\text { production }\end{array}$ & Currently many workers & Moderate-low & Moderate-low \\
\hline & $\begin{array}{l}\text { Near } \\
\text { remnant } \\
\text { pillars }\end{array}$ & Currently few workers & Moderate & Low \\
\hline
\end{tabular}

\section{Discussion}

While it is now clear that remnant pillars at the Kiirunavaara mine may influence seismic behaviour, further work needs to be done to evaluate a case that is representative of the current situation. The case presented was theoretical and used numerical modelling as a laboratory. A future case will identify the likelihood, location and geometry of remnant pillars by using loading grade. Fans which presented loading difficulties are assumed to have remnant pillars near the top of each fan. There are many of the longitudinal fans that have had low loading grades and were difficult to blast (resulting in multiple fans being blasted at the same time, reducing the blasting efficiency due to lack of expansion room). The portion of the mine with longitudinal fans has only one production drift (the fans are not staggered like when transverse fans are used), and the successful excavation of the volume relies on much success without a redundancy plan. The case that is more representative of the potential remnant pillar situation of today will provide a very interesting perspective on the risk of remnant pillars with respect to seismic behaviour.

The extent of the stress changes caused by the remnant sill pillars was significant. With this configuration of pillars, stress changes would be seen in some areas that have permanent infrastructure. This information may be very important to future planning, as the mine continues deeper into a higher stress environment.

The models only explored seismic risk through crack initiation. There is, however, another cause of seismicity: slip along pre-existing discontinuities. This can be evaluated in continuum models through, for example, the calculation of excess shear stress (Ryder 1988). It is possible that the remnant pillars can affect which, and if, pre-existing discontinuities can slip. This slip may or may not be seismic. This evaluation is planned for a later stage in the work.

Future work will address and compare actual seismic data to the model results, in particular the representation of the potential current situation based on loading grade. It is planned to compare the position of concentrations of seismicity to the stress model results. It is possible that remnant pillars may be an explanation for the concentrations of seismicity that are unaccounted for by active production (there exist 
concentrations of seismicity above active mining in what is planned to be caved material). It is important to note that the location accuracy of the seismic system needs to be accounted for in this analysis.

It was noted that although there was plastic yield in the remnant pillars, that there were also high stresses. This would create a 'rock bridge' like effect. However, using a different physical configuration of the remnant pillars may change this result, as if the pillars were shorter, there may be less confining pressure which can lead to more unravelling. It is recommended that information about blasting difficulties and loading tonnage be used to develop a better understanding of the pillar configuration.

Interestingly, the extent of plastic failure in the hanging wall of these models was not as long as the models of Vatcher (2017), which focused on a different portion of the mine. This may be related to a different study volume. Another potential explanation is the difference in how production was represented. Previous models extracted large volumes at once with a different geometry, whereas these models were more detailed in their production. More in-depth comparison and analysis should be completed.

The issue of simplified properties should also be briefly addressed. These models consist of only three materials, with homogeneous properties. This does not represent reality, and at this scale of interest, including variation may be important. For example, rock mass heterogeneity may lead to stress concentrations in already highly stressed volumes.

\section{Conclusion}

This work is the first stage in exploring if remnant pillars at the Kiirunavaara mine may be a risk factor of seismicity. Results showed that theoretical remnant sill pillars have the potential to influence the stress field at the mine-scale, as well as create significant concentrations of stress inside of the pillars, likely leading to seismic behaviour in the pillars through crack initiation. However, modelling showed that concentrating the stresses in the pillars resulted in a decrease in differential stress near production. Remnant sill pillars effectively reduced the risk associated with seismicity. Additional analyses of more realistic configurations of remnants pillars are underway. These results can be used by the mine to help plan production to reduce the risk of seismicity, through strategic creation or avoidance of remnant pillars.

\section{References}

Andrieux, P, Hudyma, MR, O'Connor, CP, Cotesta, L, Brummer, R, Hart, R, Detournay, C, \& Nelson, M 2008, 'Calibration of large-scale three-dimensional non-linear numerical models of underground mines using microseismic data', Proceedings of the 1st International FLAC/DEM Symposium on Numerical Modelling, Itasca Consulting Group, Inc., Minnneapolis, pp. 343-350.

Diederichs, MS 2000, Instability of Hard Rockmasses: The Role of Tensile Damage and Relaxation, PhD thesis, University of Waterloo, Waterloo.

Itasca Consulting Group, Inc 2018, FLAC3D, computer software, Itasca Consulting Group, Inc., Minneapolis, https://www.itascacg.com/software/flac3d

Pierce, M, Cundall, P, Mas Ivars, D, Darcel, C, Young, RP, Reyes-Montes, J \& Pettitt, W 2006, Mass Mining Technology Project: Six Monthly Technical Report, Caving Mechanics, Sub-Project No. 4.2: Research and Methodology Improvement, and Sub-Project 4.3, Case Study Application, ICG06-2292-1-Tasks 2-3-14, Itasca Consulting Group, Inc., Minneapolis.

Potvin, Y \& Wesseloo, J 2013, 'Improving seismic risk management in hardrock mines', in A Malovichko \& D Malovichko (eds), Proceedings of the 8th International Symposium on Rockbursts and Seismicity in Mines, Geophysical Survey of Russian Academy of Sciences, Obninsk, and Mining Institute of the Ural Branch of the Russian Academy of Sciences, Perm, pp. 371-386.

Ryder, JA 1988, 'Excess shear stress in the assessment of geologically hazardous situations', Journal of The South African Institute of Mining and Metallurgy, vol. 881, pp. 27-39.

Sandström, D 2003, State of Stress at the Kiirunavaara Mine: its Significance for Rock Mechanics Analysis, licentiate thesis, Luleå University of Technology, Luleå.

Sjöberg, J, Dahnér, C \& Malmgren, L 2011, 'Forensic analysis of a rock burst event at the Kiirunavaara Mine - results and implications for the future' in D Sainsbury, R Hart, C Detournay \& M Nelson (eds), Proceedings of the 2nd International FLAC/DEM Symposium, Continuum and Distinct Element Numerical Modeling in Geomechanics, Itasca International Inc., Melbourne, pp. 67-74.

Sjöberg, J, Lundman, P, Norduland, E \& Quinteiro, C 2003, 'Stability analysis of ore passes in the Kiirunavaara Mine', Technology Roadmap for Rock Mechanics: 10th Congress of the International Society for Rock Mechanics, South African Institute of Mining and Metallurgy, Johannesburg, pp. 1093-1098. 
Sjöberg, J, Perman, F, Quinteiro, C, Malmgren, L, Dahnér-Lindkvist, C \& Boskovic, M 2012, 'Numerical analysis of alternative mining sequences to minimise potential for fault slip rockbursting', Journal of Mining Technology, vol. 1214, pp. 226-235.

Vatcher, J 2017, Listening to the Story of the Rock Mass: The Integration of Conventional and Unconventional Data to Understand Rock Mass Behaviour at the Kiirunavaara Mine, PhD thesis, Luleå University of Technology, Luleå.

Vatcher, J, McKinnon, SD \& Sjöberg, J 2014, 'Mine-scale numerical modelling, seismicity and stresses at Kiirunavaara Mine, Sweden', in MR Hudyma \& Y Potvin (eds), Proceedings of the Seventh International Seminar on Deep and High Stress Mining, Australian Centre for Geomechanics, Perth, pp. 363-376.

Vatcher, J, McKinnon, SD \& Sjöberg , J 2016, 'Developing 3-D mine-scale geomechanical models in complex geological environments, as applied to the Kiirunavaara Mine', Engineering Geology, vol. 203, pp. 140-150. 